\title{
Descriptive Evaluation of National and International Hyperten- sion Treatment Guidelines: The Guideline Quality and Compre- hensiveness to provide Care to Adult with Hypertension
}

\author{
Mende Mensa Sorato*, Majid Davari and Akbar AbdollahiAsI \\ Department of Pharmacoeconomics and pharmaceutical Administration, Faculty of Pharmacy, Tehran \\ University of Medical Sciences, Iran
}

*Corresponding author: Mende Mensa Sorato, B.Pharm, MSc. PhD scholar, Department of Pharmacoeconomics and pharmaceutical Administration, Faculty of Pharmacy, Tehran University of Medical Sciences, Iran, Tel: +98-9056309138

\begin{abstract}
Background: Hypertension (Blood pressure $\geq 140 / 90$ $\mathrm{mmHg}$ ) is the modifiable risk factor responsible for a host of complications. Evidence based guidelines are important for prevention and control of hypertension. However, there is variation and inconsistencies among published guidelines concerning, diagnosis and treatment approach. Therefore, this review was conducted with intension to evaluatequality and comprehensiveness of published national adult hypertension treatment guideline, diagnosis and treatment approach in comparison with other national and international guidelines.
\end{abstract}

Methods: We selected national guidelines of five countries (USA of America, Canada, Europe, Australia and Ethiopia) and one international guideline.We used clinical guideline appraisal tool to evaluate the quality of guidelines, and comprehensiveness of the guidelines was evaluated by using a tool developed reach team.

Evidence synthesis: We qualitatively synthesized the evidence by reviewing quality and comprehensiveness ofselected guidelines.

Results: National adult hypertension treatment guideline of Ethiopia addressed only $22(64.7 \%)$ of quality appraisal tool components. The guideline is least comprehensive 15 $(51.7 \%)$. Major problems the guideline were; lack of diagnostic approach for masked, white-coat and resistant hypertension; failure to address child hood risk factors and secondary cases of hypertension. Similarly, management of hypertension in patients undergoing surgery, specific patient groups, access to medicine and social determinants of health are not addressed.

Conclusion: Quality and comprehensiveness of National hypertension guideline of Ethiopia is poor. Therefore, we recommend the guideline development committee and other relevant stakeholders to: update the blood pressure targets for elderly population, determine when to initiate and intensify antihypertensive drug therapy; address social determinants and socioeconomic status of population including maternal nutrition and Access of medicines.

\section{Keywords}

Hypertension treatment guidelines, Management of hypertension in adults, Evidence based guideline, Ethiopia

\begin{abstract}
Abbreviations
ABPM: Ambulatory Blood Pressure Monitoring; ACC/AHA: American College of Cardiology/American Heart Association; AGREE: Appraisal of Guidelines for Research \&Evaluation; ASCVD: Atherosclerotic Cardiovascular Diseases; CHD: Coronary Heart Disease; CKD: Chronic Kidney Disease; CVD: Cardiovascular Diseases; ESC/ESH: European Society of Cardiology/European Society of Hypertension; ESRD: End Stage Renal Disease; FGR: Fetal Growth Restriction; HBPM: Home Blood Pressure Monitoring; HF: Heart Failure; JNC: Joint National Committee guideline for management of raised blood pressure in adults; LDL-C: Low Density Lipoprotein- Cholesterol; MI: Myocardial Infarction; NCDs: Non-Communicable Diseases; PAD: Peripheral Arterial Disease; SPC: Single Pill Combination; SPRINT:Systolic Blood Pressure Intervention Trial; TIA: Transient Ischemic Attack
\end{abstract}

\section{Background}

Hypertension (Blood pressure $\geq 140 / 90 \mathrm{mmHg}$ ) is the modifiable risk factor responsible for host of complications. Starting at a blood pressure of $115 / 75 \mathrm{mmHg}$,

Citation: Sorato MM, Davari M, AbdollahiAsl A (2020) Descriptive Evaluation of National and International Hypertension Treatment Guidelines: The Guideline Quality and Comprehensiveness to provide Care to Adult with Hypertension. Clin Med Rev Case Rep 7:307. doi.org/10.23937/2378-3656/1410307 Accepted: May 02, 2020: Published: May 04, 2020

Copyright: (c) 2020 Sorato MM, et al. This is an open-access article distributed under the terms of the Creative Commons Attribution License, which permits unrestricted use, distribution, and reproduction in any medium, provided the original author and source are credited. 
every increase of $20 \mathrm{mmHg}$ in systolic blood pressure (SBP) and/or increase of $10 \mathrm{mmHg}$ in diastolic blood pressure (DBP) is associated with a doubling of the risk of death from stroke, heart disease, or other vascular disease [1].

Despite availability of evidence based interventions success in blood pressure control is poor globally [2]. The average Blood pressure (BP) of global adult population is above normal and less than $20 \%$ of people with hypertension have controlled their blood pressure [24]. Hypertension prevention and control in SSA is the worst in kind, fewer than $5 \%$ of those with hypertension had achieved control of their condition in SSA [5].

Prevalence of hypertension among adults increased alarmingly from $9.3 \%$ in 2011 to $19.6 \%$ in 2015 in Ethiopia [6-8]. Only $28.4 \%$ of patients were on antihypertensive medication [7]. According to the WHOSTEPs survey, $97 \%$ of hypertensive patients in Ethiopia do not receive appropriate preventive care or treatment, with only $2.8 \%$ receiving treatment and $1.5 \%$ having their hypertension controlled $[9,10]$.

Hypertension is the direct and indirect contributor of premature mortality in Ethiopia. For example; 39,571 stroke related deaths, 4,875 kidney disease related deaths, 46,943 coronary heart disease related deaths and 11,050 hypertension related deaths were reported in 2017 [11].

The world has started new movement to reduce premature mortality from non-communicable diseases. One of these movements is achieving $50 \%$ blood pressure control by 2030 from 2016 baseline (i.e. 14\%) [12]. Movement towards this target will be probably ambitious unless something is done concerning management of hypertension at national level. Reviewing the existing chronic care policies and guidelines could be a good starting point. Studies indicated that adherence to evidence based guidelines, and improving access to basic medicines are important for prevention and control of hypertension [13]. Therefore, this review was conducted with intension to evaluate quality and comprehensiveness of national hypertension treatment guideline ofEthiopia to provide comprehensive care for adults with hypertension.

\section{Methods}

\section{Guideline selection}

We included management of high blood pressure in adults (chapter four) of guidelines on clinical and programmatic management of major NCDs in Ethiopia, word heart health initiative guideline for management of CVDs, American college of cardiology guideline, Australia guideline for the diagnosis and management of hypertension in adults, hypertension Canada guideline and European society of hypertension guideline [12,1418]. We used clinical guideline appraisal tool containing
34 questions to evaluate the quality of guidelines [1922] and protocol of adapting guidelines for local context [23]. We developed seven guideline content evaluation tools (containing 29 sub-components) to assess the comprehensiveness of adult hypertension management guideline of Ethiopia.

\section{teria: \\ Guidelines are selected based on the following cri-}

- Availability of multidisciplinary guideline line development committee

- Availability of multidisciplinary guideline adaptation committee and experience of applying ADAPTE process when necessary

- Clear evidence generation process by involving methodologists for analysis and interpretation of findings

- Availability of the recent update in English language

- Universal acceptability of the guideline (i.e. world heart initiative guideline for management of hypertension).

\section{Evidence synthesis}

We qualitatively synthesized the evidence by using the following approach. First we reviewed guideline development process, adaptation process, quality and comprehensiveness of guidelines. Secondly we presented the important recommendations concerning management of hypertension and related comorbidities. Finally, we discussed the major identified gaps of Ethiopian national NCD guideline for management of hypertension in adults.

\section{Results}

\section{Guideline development and adaptation}

Evidence based guidelines can be developed or adapted from other countries. Generally, guideline development process should involve:establishing guideline development group, setting thescope, formulating review questions, identifying evidence, creating recommendations, writing draft, and sending the draft to stakeholder review, revising draft based on comments, preparing final guideline and setting review period [24-26].

HEARTs package and National guideline for major non-communicable diseases [27] are adapted from other evidence based guidelines. Clinically sound evidence based guidelines being used in one setting may be adapted for use in another country. However, adaptation process should involve clearly defined process to contextualize the guideline to specific country interest. ADAPTE is commonly used process to facilitate efficient adaptation of high-quality guidelines [23]. The goal of ADAPTE is to establish a standard of transparency and replicability of adapted guideline, hence, to improve confidence to promote the recommendations of the adapted guideline [23] (Table 1). 
Table 1: Clinical guideline Adaptation Process based on ADAPTE Process.

\begin{tabular}{|c|c|c|}
\hline S.No & Steps & Ethiopia, 2016 \\
\hline I & Set-up Preparation & \\
\hline 1 & Establish an organizing committee, working panel or resource team. & $\sqrt{ }$ \\
\hline 2 & Determine criteria for selection of guideline topic and select a topic using criteria. & $x$ \\
\hline 3 & Check if adaptation is feasible. & $\mathrm{X}$ \\
\hline 4 & Identify necessary resources and skills. & $\sqrt{ }$ \\
\hline 5 & Complete tasks of the set-up phase. & $\sqrt{ }$ \\
\hline 6 & Write the plan for adaptation. & $\sqrt{ }$ \\
\hline II & Adaptation (Scope, purpose, Search, Screen, Assess, Decide, Select and customize) & \\
\hline 7 & Determine and clarify the health-related question & $\sqrt{ }$ \\
\hline 8 & Search for guidelines and other relevant documentation. & $\sqrt{ }$ \\
\hline 9 & Screen the retrieved guidelines and record their characteristics and content. & $x$ \\
\hline 10 & Eliminate a large number of the retrieved guidelines using the AGREE instrument. & $x$ \\
\hline 11 & Assess the quality of the guideline. & $x$ \\
\hline 12 & Assess the currency of the guideline. & $\sqrt{ }$ \\
\hline 13 & Assess the content of the guideline. & $x$ \\
\hline 14 & Assess the consistency of the guideline. & $X$ \\
\hline 15 & Assess the acceptability and applicability of the recommendations. & $\mathrm{X}$ \\
\hline 16 & Review assessments & $x$ \\
\hline 17 & Select among guidelines and recommendations to create an adapted guideline. & $x$ \\
\hline 18 & Prepare a draft of the adapted guideline. & $\sqrt{ }$ \\
\hline III & Finalization (External review and acknowledgement, and final production) & \\
\hline 19 & Seek feedback on the draft adapted guideline from those who would be using it. & $x$ \\
\hline 20 & Consult with endorsement bodies & $\sqrt{ }$ \\
\hline 21 & Consult with developers of guidelines used as sources. & \\
\hline 22 & Acknowledge source documents & $x$ \\
\hline 23 & Plan for aftercare of the adapted guideline. & $\sqrt{ }$ \\
\hline 24 & Produce a final document of the guideline. & $\sqrt{ }$ \\
\hline
\end{tabular}

$\sqrt{ }$ : The process is applied or done; $X$ : The process is not done or not reported.

Table 2: Quality dimensions and items for guideline appraisal.

\section{Quality dimensions / Item label}

1. Information retrieval

1.1. Health questions and outcomes

1.2. Literature search

1.3. Literature selection

2. Evaluation of evidence

2.1. Grading of evidence

2.2. Consistency $\mathrm{b} / \mathrm{n}$ evidence \& recommendations

3. Consideration of different perspectives

3.1. Norms and values

3.2. Expert knowledge

3.3. Patient perspectives

4. Formulation of recommendations

4.1. Formulation of recommendations

5. Transferability

5.1. Comparability

5.2. Costs

\begin{tabular}{|l|l|l|l|l|l|}
\hline $\begin{array}{l}\text { A H A } \\
\mathbf{2 0 1 8}\end{array}$ & $\begin{array}{l}\text { Australia, } \\
\mathbf{2 0 1 6}\end{array}$ & $\begin{array}{l}\text { Canada, } \\
\mathbf{2 0 1 7}\end{array}$ & $\begin{array}{l}\text { HEARTs } \\
\mathbf{2 0 1 8}\end{array}$ & $\begin{array}{l}\text { ESC/ES H } \\
\mathbf{2 0 1 8}\end{array}$ & $\begin{array}{l}\text { Ethiopia, } \\
\mathbf{2 0 1 6}\end{array}$ \\
\hline$\sqrt{ }$ & $\sqrt{ }$ & $\sqrt{ }$ & $\sqrt{ }$ & $\sqrt{ }$ & $\sqrt{ }$ \\
\hline$\sqrt{ }$ & $\sqrt{ }$ & $\sqrt{ }$ & $\sqrt{ }$ & $\sqrt{ }$ & X \\
\hline$\sqrt{ }$ & $\sqrt{ }$ & $\sqrt{ }$ & $\sqrt{ }$ & $\sqrt{ }$ & X \\
\hline$\sqrt{ }$ & $\sqrt{ }$ & $\sqrt{ }$ & PA & $\sqrt{ }$ & \\
\hline$\sqrt{ }$ & $\sqrt{ }$ & $\sqrt{ }$ & PA & $\sqrt{ }$ & PA \\
\hline$\sqrt{ }$ & $\sqrt{ }$ & $\sqrt{ }$ & $\sqrt{ }$ & $\sqrt{ }$ & $\sqrt{ }$ \\
\hline$\sqrt{ }$ & $\sqrt{ }$ & $\sqrt{ }$ & $\sqrt{ }$ & $\sqrt{ }$ & $\sqrt{ }$ \\
\hline$\sqrt{ }$ & $\sqrt{ }$ & $\sqrt{ }$ & $\sqrt{ }$ & $\sqrt{ }$ & $\sqrt{ }$ \\
\hline$\sqrt{ }$ & $\sqrt{ }$ & $\sqrt{ }$ & $\sqrt{ }$ & $\sqrt{ }$ & \\
\hline$\sqrt{ }$ & $\sqrt{ }$ & $\sqrt{ }$ & $\sqrt{ }$ & $\sqrt{ }$ & $\sqrt{ }$ \\
\hline$\sqrt{ }$ & $\sqrt{ }$ & $\sqrt{ }$ & $\sqrt{ }$ & $\sqrt{ }$ & $\sqrt{ }$ \\
\hline
\end{tabular}




\begin{tabular}{|c|c|c|c|c|c|c|}
\hline 5.3. Barriers and facilitators & $\sqrt{ }$ & $\sqrt{ }$ & $\sqrt{ }$ & $\sqrt{ }$ & $\sqrt{ }$ & $x$ \\
\hline \multicolumn{7}{|l|}{ 6. Presentation of guideline content } \\
\hline 6.1. Benefits and harms & $\sqrt{ }$ & $\sqrt{ }$ & $\sqrt{ }$ & $\sqrt{ }$ & $\sqrt{ }$ & $\sqrt{ }$ \\
\hline 6.2. Link to evidence & $\sqrt{ }$ & $\sqrt{ }$ & $\sqrt{ }$ & $\sqrt{ }$ & $\sqrt{ }$ & $x$ \\
\hline \multicolumn{7}{|l|}{ 7. Alternatives } \\
\hline 7.1. Options for management & $\sqrt{ }$ & $\sqrt{ }$ & $\sqrt{ }$ & $\sqrt{ }$ & $\sqrt{ }$ & $\sqrt{ }$ \\
\hline 7.2. Exceptions & $\sqrt{ }$ & $\sqrt{ }$ & $\sqrt{ }$ & $\sqrt{ }$ & $\sqrt{ }$ & $\sqrt{ }$ \\
\hline 7.3. Patient preferences & $\sqrt{ }$ & $\sqrt{ }$ & $\sqrt{ }$ & $\sqrt{ }$ & $\sqrt{ }$ & $\mathrm{X}$ \\
\hline \multicolumn{7}{|l|}{ 8. Reliability } \\
\hline 8.1. Independent Review & $\sqrt{ }$ & $\sqrt{ }$ & $\sqrt{ }$ & $\sqrt{ }$ & $\sqrt{ }$ & $\sqrt{ }$ \\
\hline 8.2. Pilot test & $\sqrt{ }$ & $\sqrt{ }$ & $\sqrt{ }$ & $\sqrt{ }$ & $\sqrt{ }$ & $x$ \\
\hline \multicolumn{7}{|l|}{ 9. Scope } \\
\hline 9.1. Rationale and objective & $\sqrt{ }$ & $\sqrt{ }$ & $\sqrt{ }$ & $\sqrt{ }$ & $\sqrt{ }$ & $\sqrt{ }$ \\
\hline 9.2. Guideline topic & $\sqrt{ }$ & $\sqrt{ }$ & $\sqrt{ }$ & $\sqrt{ }$ & $\sqrt{ }$ & $\sqrt{ }$ \\
\hline 9.3. Practice setting & $\sqrt{ }$ & $\sqrt{ }$ & $\sqrt{ }$ & $\sqrt{ }$ & $\sqrt{ }$ & $\sqrt{ }$ \\
\hline 9.4. Patient population & $\sqrt{ }$ & $\sqrt{ }$ & $\sqrt{ }$ & $\sqrt{ }$ & $\sqrt{ }$ & $x$ \\
\hline 9.5. Provider population & $\sqrt{ }$ & $\sqrt{ }$ & $\sqrt{ }$ & $\sqrt{ }$ & $\sqrt{ }$ & $\sqrt{ }$ \\
\hline 10. Independence & $\sqrt{ }$ & $\sqrt{ }$ & $\sqrt{ }$ & $\sqrt{ }$ & $\sqrt{ }$ & $\sqrt{ }$ \\
\hline 10.1. Guideline development group & $\sqrt{ }$ & $\sqrt{ }$ & $\sqrt{ }$ & $\sqrt{ }$ & $\sqrt{ }$ & $\sqrt{ }$ \\
\hline 10.2. Guideline development organization \& funding & $\sqrt{ }$ & $\sqrt{ }$ & $\sqrt{ }$ & $\sqrt{ }$ & $\sqrt{ }$ & $\sqrt{ }$ \\
\hline 10.3. Conflicts of interest & $\sqrt{ }$ & $\sqrt{ }$ & $\sqrt{ }$ & $\sqrt{ }$ & $\sqrt{ }$ & $\sqrt{ }$ \\
\hline \multicolumn{7}{|l|}{ 11. Clarity and presentation } \\
\hline 11.1. Clarity & $\sqrt{ }$ & $\sqrt{ }$ & $\sqrt{ }$ & $\sqrt{ }$ & $\sqrt{ }$ & $\sqrt{ }$ \\
\hline 11.2. Presentation & $\sqrt{ }$ & $\sqrt{ }$ & $\sqrt{ }$ & $\sqrt{ }$ & $\sqrt{ }$ & $\sqrt{ }$ \\
\hline \multicolumn{7}{|l|}{ 12. Updating } \\
\hline 12. 1. Currentness & $\sqrt{ }$ & $\sqrt{ }$ & $\sqrt{ }$ & $\sqrt{ }$ & $\sqrt{ }$ & $\mathrm{X}$ \\
\hline 12.2. Scheduled review & $\sqrt{ }$ & $\sqrt{ }$ & $\sqrt{ }$ & $\sqrt{ }$ & $\sqrt{ }$ & $\mathrm{X}$ \\
\hline \multicolumn{7}{|l|}{ 13. Dissemination, Implementation, Evaluation } \\
\hline 13.1. Dissemination & $\sqrt{ }$ & $\sqrt{ }$ & $\sqrt{ }$ & $\sqrt{ }$ & $\sqrt{ }$ & $\sqrt{ }$ \\
\hline 13.2. Implementation & $\sqrt{ }$ & $\sqrt{ }$ & $\sqrt{ }$ & $\sqrt{ }$ & $\sqrt{ }$ & $\sqrt{ }$ \\
\hline 13.3. Evaluation & $\sqrt{ }$ & $\sqrt{ }$ & $\sqrt{ }$ & $\sqrt{ }$ & $\sqrt{ }$ & $\mathrm{X}$ \\
\hline
\end{tabular}

$\sqrt{ }$ : Yes; X: No; PA: Partially acceptable for guidelines that are copied from other guidelines.

National hypertension treatment guideline of Ethiopia, satisfies only $12(50 \%)$ of adaptation process steps. Major problems areas were; there was no assigned multidisciplinary guideline adaptation committee, lack of end-user involvement, and guideline selection criteria.In addition to this, quality, content, consistency and acceptability of each guideline were not appropriately assessed. Finally, the draft document was not communicated to stakeholders, and the feedback acknowledgement was not done [27].

Quality of clinical guidelines is critical for provision of appropriate care for patients who need it with reasonable cost. Quality clinical guideline should have the following components: information retrieval process, evidence evaluation form different perspectives, developingevidence based and clear recommendations [1922].

Based on quality appraisal tool, Ethiopian national guideline has addressed only 22 (64.7\%) questions of the quality appraisal tool [27] (Table 2). In addition to this, the guideline is the least comprehensive among guidelines evaluated 15 (51.7\%) [27] (Table 3). This could be the contributing factor for probably the poorest blood pressure control among hypertensive patients. According to the WHOSTEPs survey, 97\% of hypertensive patients in Ethiopia do not receive appropriate preventive care or treatment, with only $2.8 \%$ receiving treatment and $1.5 \%$ having their hypertension controlled $[9,10]$.

\section{Diagnosis of hypertension}

Appropriate diagnosis of blood pressure is the first critical step in management of hypertension. Common errors that can occur during BP measurement include: Faulty BP apparatus (Cuff too smallor too large) and Patient Related [Pain or anxiety, Bladder distension, Acute smoking, caffeine, ethanol ( $<2$ hours)] and talking during BP reading) [1,28-30]. Generally, BP falls by $10-$ $20 \%$ fromdaytime to nighttime, and this could be mainly 
Table 3: Evaluation of hypertension guideline contents for providing comprehensive care for adult patients.

\begin{tabular}{|c|c|c|c|c|c|c|c|}
\hline S.No & Contents & $\begin{array}{l}\text { AHA, } \\
2018\end{array}$ & $\begin{array}{l}\text { Australia, } \\
2016\end{array}$ & $\begin{array}{l}\text { Canada, } \\
2017\end{array}$ & $\begin{array}{l}\text { HEARTs, } \\
2018\end{array}$ & $\begin{array}{l}\text { ESC/ESH, } \\
2018\end{array}$ & $\begin{array}{l}\text { Ethiopia, } \\
2016\end{array}$ \\
\hline 1 & Introduction to hypertension & & & & & & \\
\hline 1.1 & Definition of hypertension & $\sqrt{ }$ & $\sqrt{ }$ & $\sqrt{ }$ & $\sqrt{ }$ & $\sqrt{ }$ & $\sqrt{ }$ \\
\hline 1.2 & BP components & $\sqrt{ }$ & $\sqrt{ }$ & $\sqrt{ }$ & $\sqrt{ }$ & $\sqrt{ }$ & $\sqrt{ }$ \\
\hline 1.3 & Population at risk & $\sqrt{ }$ & $\sqrt{ }$ & $\sqrt{ }$ & $\sqrt{ }$ & $\sqrt{ }$ & $\sqrt{ }$ \\
\hline 1.4 & Hypertension and chronic illnesses & $\sqrt{ }$ & $\sqrt{ }$ & $\sqrt{ }$ & $\sqrt{ }$ & $\sqrt{ }$ & $\sqrt{ }$ \\
\hline 2 & Diagnosis of hypertension & & & & & & \\
\hline 2.1 & Methods of BP measurement & $\sqrt{ }$ & $\sqrt{ }$ & $\sqrt{ }$ & $\sqrt{ }$ & $\sqrt{ }$ & $\sqrt{ }$ \\
\hline 2.2 & True hypertension & $\sqrt{ }$ & $\sqrt{ }$ & $\sqrt{ }$ & $\sqrt{ }$ & $\sqrt{ }$ & $\sqrt{ }$ \\
\hline 2.3 & Masked hypertension & $\sqrt{ }$ & $\sqrt{ }$ & $\sqrt{ }$ & $\sqrt{ }$ & $\sqrt{ }$ & $x$ \\
\hline 2.4 & White coat hypertension & $\sqrt{ }$ & $\sqrt{ }$ & $\sqrt{ }$ & $\sqrt{ }$ & $\sqrt{ }$ & $\mathrm{x}$ \\
\hline 2.5 & Cardiovascular risk stratification & $\sqrt{ }$ & $\sqrt{ }$ & $\sqrt{ }$ & $\sqrt{ }$ & $\sqrt{ }$ & $\sqrt{ }$ \\
\hline 3 & Cases of hypertension & $\sqrt{ }$ & $\sqrt{ }$ & $\sqrt{ }$ & $\sqrt{ }$ & $\sqrt{ }$ & $\mathrm{x}$ \\
\hline 3.1 & Genetic predisposition & $\sqrt{ }$ & $\sqrt{ }$ & $\sqrt{ }$ & $\sqrt{ }$ & $\sqrt{ }$ & $\mathrm{x}$ \\
\hline 3.2 & Behavioral risk factors & $\sqrt{ }$ & $\sqrt{ }$ & $\sqrt{ }$ & $\sqrt{ }$ & $\sqrt{ }$ & $x$ \\
\hline 3.3 & Childhood risk factors & $\sqrt{ }$ & $\sqrt{ }$ & $\sqrt{ }$ & $\sqrt{ }$ & $\sqrt{ }$ & $\mathrm{x}$ \\
\hline 3.4 & Secondary cases hypertension & $\sqrt{ }$ & $\sqrt{ }$ & $\sqrt{ }$ & $\sqrt{ }$ & $\sqrt{ }$ & $x$ \\
\hline 4 & Management of hypertension & & & & & & \\
\hline 4.1 & Non-pharmacological interventions & $\sqrt{ }$ & $\sqrt{ }$ & $\sqrt{ }$ & $\sqrt{ }$ & $\sqrt{ }$ & $\sqrt{ }$ \\
\hline 4.2 & Pharmacological therapy & $\sqrt{ }$ & $\sqrt{ }$ & $\sqrt{ }$ & $\sqrt{ }$ & $\sqrt{ }$ & $\sqrt{ }$ \\
\hline 4.3 & Management of hypertension with comorbidities & $\sqrt{ }$ & $\sqrt{ }$ & $\sqrt{ }$ & $\sqrt{ }$ & $\sqrt{ }$ & $\sqrt{ }$ \\
\hline 5 & Special groups (race, ethnicity, elderly) & $\sqrt{ }$ & $\sqrt{ }$ & $\sqrt{ }$ & $\sqrt{ }$ & $\sqrt{ }$ & $x$ \\
\hline 6 & Other considerations & & & & & & \\
\hline 6.1 & Resistant hypertension & $\sqrt{ }$ & $\sqrt{ }$ & $\sqrt{ }$ & $\sqrt{ }$ & $\sqrt{ }$ & $\mathrm{x}$ \\
\hline 6.2 & Hypertension crisis & $\sqrt{ }$ & $\sqrt{ }$ & $\sqrt{ }$ & $\sqrt{ }$ & $\sqrt{ }$ & $\sqrt{ }$ \\
\hline 6.3 & Hypertension and pregnancy & $\sqrt{ }$ & $\sqrt{ }$ & $\sqrt{ }$ & $\sqrt{ }$ & $\sqrt{ }$ & $x$ \\
\hline 6.4 & Hypertension and sexual dysfunctions & $\sqrt{ }$ & $\sqrt{ }$ & $\sqrt{ }$ & $\sqrt{ }$ & $\sqrt{ }$ & $\sqrt{ }$ \\
\hline 6.5 & Hypertension and patients undergoing surgery & $\sqrt{ }$ & $\sqrt{ }$ & $\sqrt{ }$ & $\sqrt{ }$ & $\sqrt{ }$ & $\mathrm{x}$ \\
\hline 7 & Strategies to improve BP control & & & & & & \\
\hline 7.1 & Strategies to improve treatment Adherence & $\sqrt{ }$ & $\sqrt{ }$ & $\sqrt{ }$ & $\sqrt{ }$ & $\sqrt{ }$ & $\sqrt{ }$ \\
\hline 7.2 & Structure Team-based care for hypertension & $\sqrt{ }$ & $\sqrt{ }$ & $\sqrt{ }$ & $\sqrt{ }$ & $\sqrt{ }$ & $\sqrt{ }$ \\
\hline 7.3 & $\begin{array}{l}\text { Health information technology to improve BP } \\
\text { control }\end{array}$ & $\sqrt{ }$ & $\sqrt{ }$ & $\sqrt{ }$ & $\sqrt{ }$ & $\sqrt{ }$ & $\sqrt{ }$ \\
\hline 7.4 & Clear Care plan and Dose intensification protocol & $\sqrt{ }$ & $\sqrt{ }$ & $\sqrt{ }$ & $\sqrt{ }$ & $\sqrt{ }$ & $\mathrm{x}$ \\
\hline 7.5 & Monitoring and follow-up & $\sqrt{ }$ & $\sqrt{ }$ & $\sqrt{ }$ & $\sqrt{ }$ & $\sqrt{ }$ & $\sqrt{ }$ \\
\hline 7.6 & Health Literacy & $\sqrt{ }$ & $\sqrt{ }$ & $\sqrt{ }$ & $\sqrt{ }$ & $\sqrt{ }$ & $\mathrm{x}$ \\
\hline 7.7 & Access to health insurance \&medications & $\sqrt{ }$ & $\sqrt{ }$ & $\sqrt{ }$ & $\sqrt{ }$ & $\sqrt{ }$ & $\sqrt{ }$ \\
\hline 7.8 & Social determinants & $\sqrt{ }$ & $\sqrt{ }$ & $\mathrm{x}$ & $\mathrm{x}$ & $\sqrt{ }$ & $\mathrm{x}$ \\
\hline
\end{tabular}

$\sqrt{ }$ : The guideline addresses topics; $X$ : The topic is not included in the guideline; ESC/ESH: European Society of Cardiology and the European Society of Hypertension: ACC/AHA: American College of Cardiology/ American heart Association.

explained by physical activity than a circadian rhythm [31].

A 24-hour ambulatory pressure monitoring is ideal method for hypertension diagnosis. This is because white-coat and masked hypertension can be identified, provide stronger prognostic evidence, and night-time readings can be recorded. However, it is expensive, less available, and not feasible in most countries [1].

Laboratory investigations are required as diagnos- tic aid or confirmatory. Common laboratory investigations include: measuring fasting blood glucose, complete blood count, lipid profile, serum creatinine with estimated glomerular filtration rate, serum electrolytes, thyroid-stimulating hormone, urinalysis and electrocardiogram, echocardiogram, uric acid and urinary albumin to creatinine ratio $[1,18]$.

All guidelines agreed on importance of proper methods and timing of BP management for diagnosis of hy- 
pertension.However, Ethiopian national guideline did not address diagnostic work-up for white-coat and masked hypertension. It is important to know the prevalence of both white-coat and masked hypertension to provide appropriate care for patients with hypertension. Ignoring white-coat hypertension may lead over estimation of hypertension and unnecessary treatment. While, ignoring masked hypertension lead to under estimation of hypertension, delayed treatment initiation and associated complications.

\section{Blood pressure targets and when to initiate phar- macological therapy}

There are two global guidelines for treatment and control of blood pressure in adults: Joint National Committee guideline for management of raised blood pressure in adults 7 and 8 (JNC 7 and 8) [32,33].

Global heart health (HEARTs) technical package [15] has similar hypertension diagnostic thresholds and targets of treatment with JNC 7 recommendations. Nation- al guidelineof Ethiopia adopted JNC 7 and 8 hypertension diagnosis thresholds and targets [27]. Concerning hypertension diagnosis thresholds, it included additional BP category (severe hypertension BP $\geq 180 / 110$ $\mathrm{mmHg}$ ). Similarly, it recommends BP targets of JNC 8 but increased age of targeting $B P<150 / 90 \mathrm{mmHg}$ from $\geq 60$ years to $>75$ years [27] (Table 4).

Regarding Blood pressure targets, ACC and HEART's guidelines target $\mathrm{BP}<130 / 80 \mathrm{mmHg}$ for high risk and $\mathrm{BP}<140 / 90 \mathrm{mmHg}$ for others. Australia and Canada guidelines target $\mathrm{BP}<120 / 80$ for high risk, $\mathrm{BP}<140 / 90$ $\mathrm{mmHg}$ for others. Hypertension Canada targets BP < $130 / 80 \mathrm{mmHg}$ for diabetic patients. European cardiology and hypertension society targets $<140 / 90 \mathrm{mmHg}$ in all patients, if treatment is tolerable $<130 / 80 \mathrm{mmHg}$, $120-129 /<80 \mathrm{mmHg}$ for patients less than 65 years old and $130-139 /<80 \mathrm{mmHg}$ in $\geq 65$ years. Ethiopian guideline targets $B P<140 / 90 \mathrm{mmHg}$ for adults $18-75$ years and $\mathrm{BP}<150 / 90 \mathrm{mmHg}$ for patients above 75 years $[1,12,14-18,34]$ (Table 4).

Table 4: Comparison of Blood Pressure Targets and time to initiate pharmacologic treatment.

\begin{tabular}{|c|c|c|c|c|c|}
\hline \multirow[t]{2}{*}{ Guidelines } & \multirow[t]{2}{*}{ BP targets } & \multirow[t]{2}{*}{ BP classification } & \multicolumn{2}{|c|}{$\begin{array}{l}\text { BP thresholds } \\
(\mathrm{mmHg})\end{array}$} & \multirow[t]{2}{*}{$\begin{array}{l}\text { When to initiate Pharmacologic } \\
\text { treatment }\end{array}$} \\
\hline & & & SBP & DBP & \\
\hline \multirow[t]{4}{*}{ JNC 7, 2003} & $<140 / 90 \mathrm{mmHg}$ & Normal & $<120$ & $<80$ & $\geq 140 \mathrm{mmHg}$ for $30-59$ years \\
\hline & \multirow{3}{*}{$\begin{array}{l}<130 / 80 \mathrm{mmHg} \text { for } \\
\text { those with diabetes } \\
\text { or Chronic Kidney } \\
\text { disease }\end{array}$} & Prehypertension & $120-139$ & $80-89$ & \\
\hline & & Stage I hypertension & $140-159$ & $90-99$ & \\
\hline & & Stage 2 hypertension & $\geq 160$ & $\geq 100$ & \\
\hline \multirow[t]{3}{*}{ JNC 8, 2014} & \multirow{2}{*}{$\begin{array}{l}<150 / 90 \mathrm{mmHg} \text { for } \\
\text { patients } \geq 60 \text { years }\end{array}$} & \multirow{2}{*}{\multicolumn{3}{|c|}{$\begin{array}{l}\text { JNC 8, did not discuss hypertension diagnostic } \\
\text { thresholds }\end{array}$}} & $\geq 140 \mathrm{mmHg}$ for $30-59$ years \\
\hline & & & & & $\geq 150 / 90 \mathrm{mmHg}$ for $60 \mathrm{yrs}$ and older \\
\hline & \multicolumn{4}{|c|}{$<140 / 90 \mathrm{mmHg}$ for patients < 60, diabetes and CKD } & $\begin{array}{l}\text { Based on expert opinion for } 18-29 \\
\text { years }\end{array}$ \\
\hline \multirow[t]{4}{*}{ ACC/AHA, 2018} & \multirow[t]{4}{*}{$<130 / 80 \mathrm{~mm} \mathrm{Hg}$} & Normal & $<120$ & $<80$ & \multirow{2}{*}{$\begin{array}{l}\geq 140 / 90 \mathrm{mmHg} \text { for low risk }(10-\mathrm{yrs} \\
\text { CVD risk }<10 \%)\end{array}$} \\
\hline & & Elevated & $120-129$ & $<80$ & \\
\hline & & Stage 1 hypertension & $130-139$ & $80-89$ & $\geq 130 / 80 \mathrm{mmHg}$ for all others \\
\hline & & Stage 2 hypertension & $\geq 140$ & $\geq 90$ & \\
\hline \multirow{5}{*}{$\begin{array}{l}\text { National NCD } \\
\text { guidelines of } \\
\text { Ethiopia, } 2016\end{array}$} & $<140 / 90 \mathrm{mmHg}$ & Normal & $<120$ & $<80$ & \\
\hline & \multirow{4}{*}{$\begin{array}{l}<150 / 90 \mathrm{mmHg} \text { for } \\
\text { patients }>75 \text { years }\end{array}$} & Pre-hypertension & $120-139$ & $80-89$ & $\geq 160 / 100 \mathrm{mmHg}$ low risk \\
\hline & & Stage 1 hypertension & $140-159$ & $90-99$ & $\geq 140 / 90 \mathrm{mmHg}$ for high risk \\
\hline & & Stage 2 hypertension & $\geq 160$ & $\geq 100$ & \multirow{2}{*}{$\begin{array}{l}\geq 130 / 80 \mathrm{mmHg} \text { for very high risk } \\
\text { patients }\end{array}$} \\
\hline & & Severe hypertension & $\geq 180$ & $\geq 110$ & \\
\hline \multirow{4}{*}{$\begin{array}{l}\text { HEARTs } \\
\text { package for } \\
\text { CVDs, } 2018\end{array}$} & $<140 / 90 \mathrm{mmHg}$ & Normal & $<120$ & $<80$ & \\
\hline & \multirow{3}{*}{$\begin{array}{l}<130 / 80 \mathrm{mmHg} \text { for } \\
\text { patients with High } \\
\text { risk of CVDs and } \\
\text { diabetic patients }\end{array}$} & Prehypertension & $120-139$ & $80-89$ & $\geq 140 / 90 \mathrm{mmHg}$ \\
\hline & & Stage I hypertension & $140-159$ & $90-99$ & $\begin{array}{l}\geq 130 / 80 \mathrm{mmHg} \text { for high risk (CHD, } \\
\text { Cerebrovascular disease) }\end{array}$ \\
\hline & & Stage 2 hypertension & $\geq 160$ & $\geq 100$ & \\
\hline \multirow[t]{4}{*}{$\begin{array}{l}\text { Hypertension } \\
\text { Canada, } 2017\end{array}$} & $\begin{array}{l}<120 / 80 \mathrm{mmHg} \\
\text { High risk }\end{array}$ & Normal & $<120$ & $<80$ & $\geq 120 / 80 \mathrm{mmHg}$ for High risk \\
\hline & $\begin{array}{l}<130 / 80 \mathrm{mmHg} \\
\text { diabetics }\end{array}$ & Elevated & $120-129$ & $<80$ & $\geq 130 / 80 \mathrm{mmHg}$ for diabetics \\
\hline & \multirow{2}{*}{$\begin{array}{l}<140 / 90 \mathrm{mmHg} \text { for } \\
\text { others }\end{array}$} & Stage 1 hypertension & $130-139$ & $80-89$ & $\geq 140 / 90 \mathrm{mmHg}$, Moderate risk \\
\hline & & Stage 2 hypertension & $\geq 140$ & $\geq 90$ & $\geq 160 / 100 \mathrm{mmHg}$, low risk \\
\hline
\end{tabular}




\begin{tabular}{|c|c|c|c|c|c|}
\hline \multirow{7}{*}{$\begin{array}{l}\text { Hypertension } \\
\text { guideline } \\
\text { Australia, } 2016\end{array}$} & \multirow{3}{*}{$\begin{array}{l}<120 / 80 \mathrm{mmHg} \\
\text { High risk }\end{array}$} & Optimal & $<120$ & $<80$ & \\
\hline & & Normal & $120-129$ & $80-84$ & $\geq 120 / 80 \mathrm{mmHg}$, High risk \\
\hline & & High normal & $130-139$ & $85-89$ & $\geq 140 / 90 \mathrm{mmHg}$, Moderate risk \\
\hline & \multirow{4}{*}{$\begin{array}{l}<140 / 90 \mathrm{mmHg} \text { for } \\
\text { others }\end{array}$} & Grade 1 (Mild) & $140-159$ & $90-99$ & $\geq 160 / 100 \mathrm{mmHg}$, low risk \\
\hline & & Grade 2 (Moderate) & $160-179$ & $100-109$ & \\
\hline & & Grade 3 (Severe) & $\geq 180$ & $\geq 110$ & \\
\hline & & Isolated systolic & $>140$ & $<90$ & \\
\hline \multirow{7}{*}{$\begin{array}{l}\text { ESC/ } \\
\text { ESHGuidelines, } \\
2018\end{array}$} & \multirow{3}{*}{$\begin{array}{l}<140 / 90 \mathrm{mmHg} \\
\text { in all patients, if } \\
\text { tolerable } \\
<130 / 80 \mathrm{mmHg}\end{array}$} & Optimal & $<120$ & $<80$ & \multirow{2}{*}{$\begin{array}{l}130-139 / 80-89 \mathrm{mmHg} \text {, Consider in } \\
\text { very high risk }\end{array}$} \\
\hline & & Normal & $120-129$ & $80-84$ & \\
\hline & & High normal & $130-139$ & $85-89$ & \multirow{3}{*}{$\begin{array}{l}140-159 / 90-99 \mathrm{mmHg} \text {, immediately } \\
\text { start in very high risk and } 3-6 \text { months } \\
\text { lifestyle intervention for low risk }\end{array}$} \\
\hline & \multirow{2}{*}{$\begin{array}{l}120-129 /<80 \\
\mathrm{mmHg} \text { in }<65 \\
\text { years }\end{array}$} & Grade 1 Hypertension & $140-159$ & $90-99$ & \\
\hline & & Grade 2 Hypertension & $160-179$ & $100-109$ & \\
\hline & \multirow{2}{*}{$\begin{array}{l}130-139 /<80 \\
\mathrm{mmHg} \text { in } \geq 65 \text { years }\end{array}$} & Grade 3 Hypertension & $\geq 180$ & $\geq 110$ & \multirow{2}{*}{$\begin{array}{l}\geq 160 / 100, \text { immediately start and } \\
\text { aim to control BP in } 3 \text { months }\end{array}$} \\
\hline & & $\begin{array}{l}\text { Isolated Systolic } \\
\text { Hypertension }\end{array}$ & $\geq 140$ & $<90$ & \\
\hline
\end{tabular}

BP indicates blood pressure (based on an average of $\geq 2$ careful readings obtained on $\geq 2$ occasions). Patients with SBP and DBP in two different categories should be classified in the higher category. BP: Blood Pressure; TIA: Transient Ischemic Attack; Low risk: no CVD or CV risk factors or absolute CVD 5 year risk < 5\% ; Moderate risk: absolute 5 year CVD risk, 10-15\%; High Risk 10 -year CVD risk 20-30\% and Very high risk 10-year CVD risk $>30 \%$.

\section{Treatment of hypertension}

A Comprehensive treatment for hypertensive patients is believed to improve movement towards reduction of related morbidity and mortality. Comprehensive hypertension treatment approach should include due consideration to social determinants, non-pharmacologic and anti-hypertensive pharmacotherapy [35]. Despite this evidence there are inconsistencies and differences in treatment approach and when to treat hypertensive patients in published guidelines, because of which physicians sometimes have to individualize the therapy, based on specific patient characteristics and response to treatment [36].

Social determinants: Less attention is given to social determinants of health in the today's healthcare, despite their huge impact on health related patient outcomes. Findings from different literatures indicated that clinical care contributes only $10-20 \%$ to health outcomes of a person even in their best possible stand. Socioeconomic factors, health behavior and factors related to the physical environment are estimated to account for up to $80 \%$ of health outcomes [37].

Poverty cases difficulty for treatment recommendations (meal plan, medication, indoor pollution, etc.). Similarly, Populations living below the poverty level have higher prevalence of cigarette smoking and less likely to quit. Addressing poverty alone can improve life expectancy by (2-4-5.4 years) [38-42]. Spending on Education, with expanded coverage improves life expectancy on average by 1.19 years. Low level of education is associated risky behaviors like substance, unsafe sexual practice, and poor dietary management [43].

Nonpharmacological Interventions: Behavior and life style factors account for $30 \%$ of health related patient outcomes. Their effect may be more pronounced in case of chronic illness like hypertension [37]. The following nonpharmacological interventions are recommended as first line management for hypertension individually or in combination with antihypertensive drugs. These include; weight loss for obese and overweight individuals, healthy diet, reducing dietary Sodium, enhancing dietary potassium intake, physical activity and reducing harmful use of alcohol. [18,44-51]. Perfect adherence nonpharmacological therapy can reduce systolic blood pressure (SBP) on average by $36 \mathrm{mmHg}$ for hypertensive patients.

Pharmacological treatment: Concerning when to initiate pharmacologic therapy for hypertension guidelines have slight variation. For example, Australia hypertension treatment guideline recommends initiating antihypertensive pharmacologic therapy at $B P \geq 120 / 80$ $\mathrm{mmHg}$ for high-risk patients, $\geq 140 / 90 \mathrm{mmHg}$ for moderate risk and $\geq 160 \mathrm{mmHg}$ for low risk patients [16]. European Cardiology society guideline recommends initiation antihypertensive therapy if BP 130-139/80$89 \mathrm{mmHg}$ for very high risk, after 3-6 months trial of lifestyle intervention if BP 140-159/90-99 $\mathrm{mmHg}$ and immediately for all patients if $B P \geq 160 / 100 \mathrm{mmHg}$ [18].

Canada hypertension guideline has similar recommendation except that, initiating antihypertensive pharmacologic therapy for diabetic patients is at $\mathrm{BP} \geq$ $130 / 80 \mathrm{mmHg}$ [17]. American Heart association guideline [1] and WHO HEART's package guideline [15] recommend initiating antihypertensive pharmacologic therapy at $\mathrm{BP} \geq 130 / 80 \mathrm{mmHg}$ for high risk patients and $B P \geq 140 / 90 \mathrm{mmHg}$ for others. Ethiopian NCD guideline for major diseases recommends antihypertensive 
pharmacologic therapy for patients with BP $\geq 160 / 100$ $\mathrm{mmHg}$ and $\mathrm{BP} \geq 140 / 90 \mathrm{mmHg}$ for high risk (i.e.10 year CVD risk 20-20\%), patients with $B P \geq 140 / 90 \mathrm{mmHg}$ for high risk and 10 -year CVD risk below $20 \%$ should continue lifestyle management [27] (Table 4).

All guidelines agreed on use of angiotensin converting enzyme inhibitors (ACEls), angiotensin receptor blockers (ARBs), beta-blockers, calcium channel blockers (CCBs), and diuretics (thiazides and thiazide-like drugs) as the basis of antihypertensive treatment strategies. Similarly, all guidelines recommended Combination treatment is recommended for most hypertensive patients as initial therapy. Preferred combinations should comprise ACEI or an ARB with a CCBs or diuretics (thiazides and thiazide-like drugs). If $B P$ is not controlled with a two-drug combination, treatment should be increased to a three-drug combination, usually ACEI/ARB $+\mathrm{CCB}+$ thiazide, preferably as a single pill combination (SPC) [12,14-18].

Treatment algorithm and dose intensification: One of the important components of quality guidelines is providing simplified management protocol or algorithms in the form of tables, charts or graphs. We selected WHO HEART's technical package guideline as reference concerning treatment algorithm and antihypertensive drug dose intensification (Figure 1 and

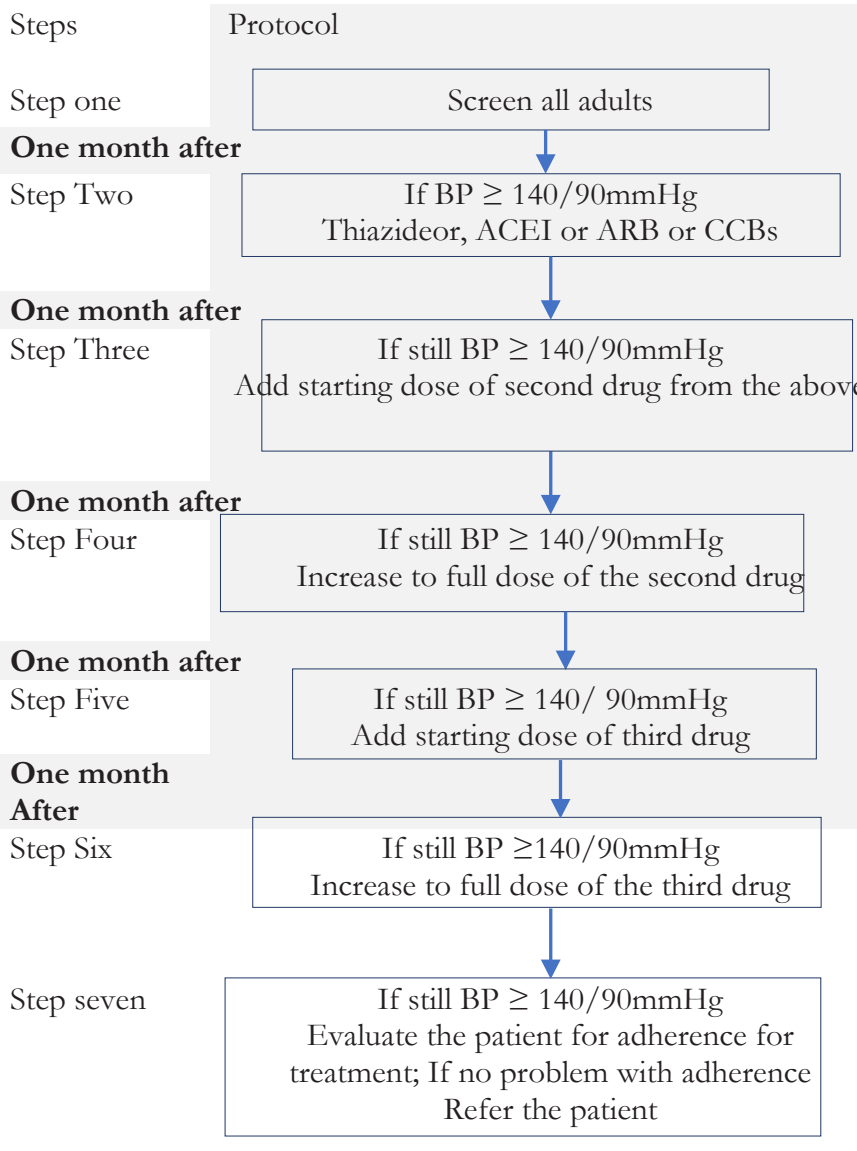

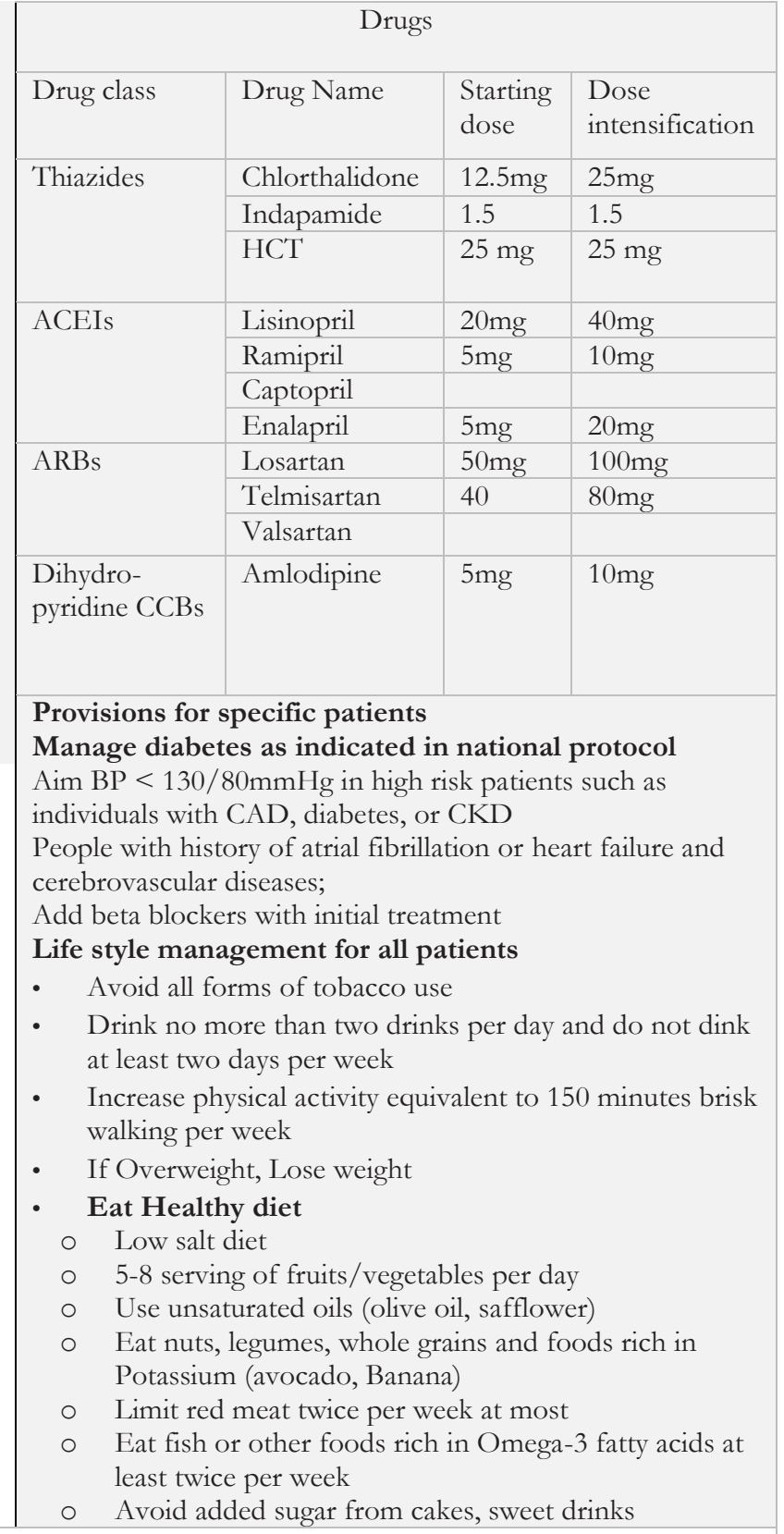

Note: Hypokalemia is common side effect during intensification of thiazides, monitor more frequently

ACEIs case chronic dry cough in almost $10 \%$ of patients and rarely angioedema: ACEIs are also contra indicated in patients with advanced chronic Kidney disease (CKD), aortic stenosis and history allergy and angioedema

Thiazides, ACEIs and ARBs as first line are contraindicated in pregnant women or who could become pregnant.

Figure 1: World Hypertension League and the International Society of Hypertension: Hypertension treatment Protocol by using single first line agent. 


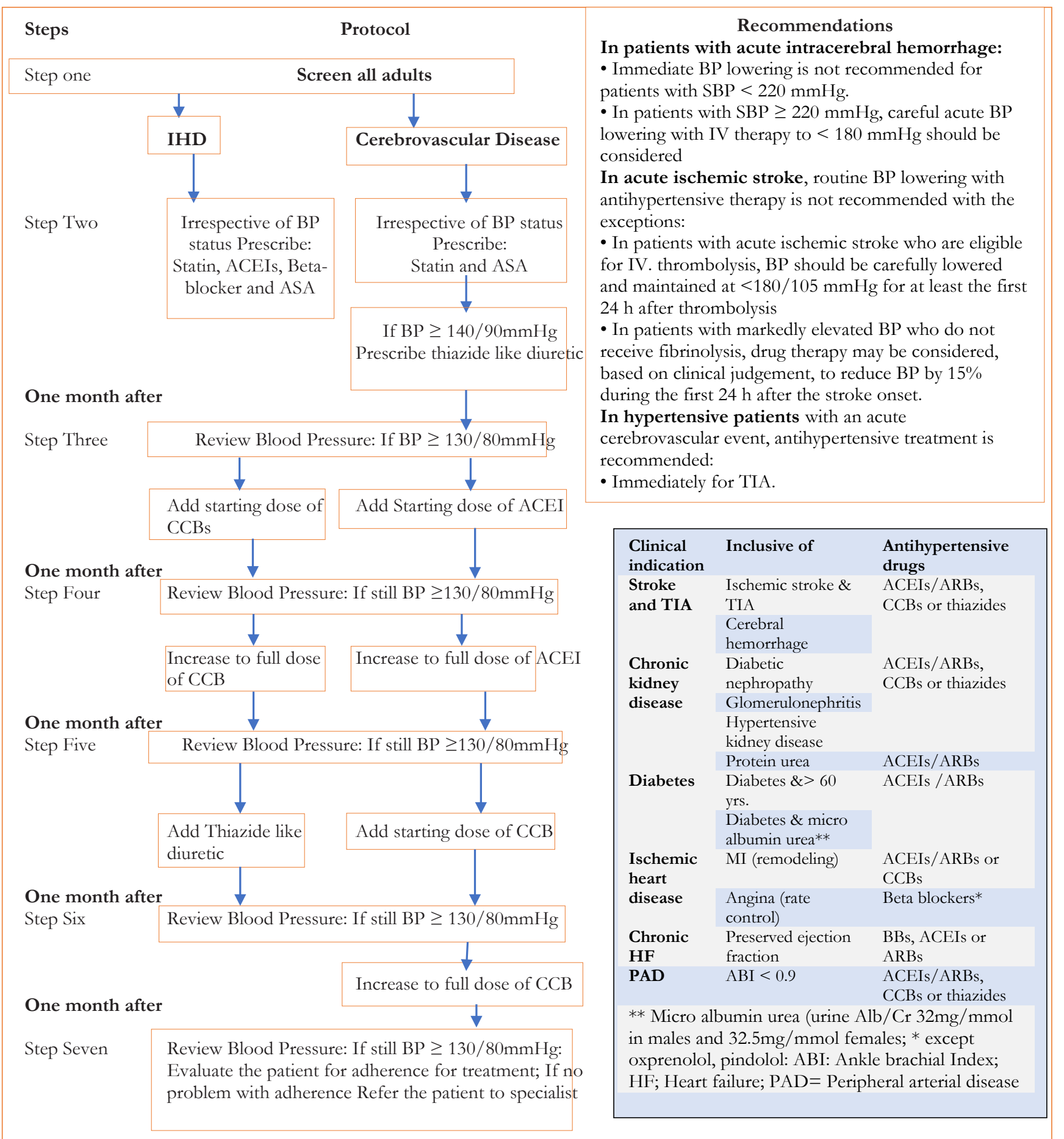

Figure 2: Protocol for treating patients with Ischemic heart disease by using of anti-hypertensive drugs.

Figure 2). Providing guide when and how to intensify to drug treatment is important to improve BP control. However, this approach was not addressed in Ethiopian national hypertension guideline.

\section{Access to Medicines for CVDs}

One of global voluntary targets NCD control is ensuring $80 \%$ availability of affordable and quality essential drugs for treatment of NCDs in both public and private facilities. However, According to the third national pharmaceutical sector survey median percentage availability of medicines used for chronic illnesswas $54.55 \%$ and none of essential medicines for NCDs are affordable
[52]. This unaffordability of medicine is contributing poor adherence of hypertensive patients as evidenced by only $28.4 \%$ of hypertensive patients were taking medications prescribed by professionals. In addition to this, $15.6 \%$ individuals with raised BP (SBP $\geq 140$ and/or $\mathrm{DBP} \geq 90 \mathrm{mmHg}$ ) were not currently not on antihypertensive medication [7].

It is recommended to decrease out of pocket payment (OPP) to $15-20 \%$ of total health expenditure to make financial limitation to healthcare access. Out of pocket payment (OPP) expense was $33.8 \%$ in 2017 $[50,53,54]$. Given the poverty level of nearly one-quarter of the population in Ethiopia, it is likely that house- 
holds who decide to use health services could easily slip into poverty. Thus, the government should improve coverage of community health insurance schemes which is under pilot in some regions. It should also start social health insurance for the formal sectors.

Healthcare service delivery system availability and readiness survey indicated that thegeneral service readiness index was $54 \%$. Only $9 \%$ of facilities had guidelines for CVD diagnosis and management. The percentage availability trained staff for CVD diagnosis and management was $7 \%$. Availability of Aspirin (53\%), hydrochlorothiazide (37\%), ACEls (25\%), calcium channel blockers $(20 \%)$, metformin $(19 \%)$ and beta blockers $(15 \%)$. The percent of facilities with all of these items needed to provide CVD care was $(1 \%)[9,55]$.

Another important factor that could affect blood pressure control in Ethiopia is Health worker density and distribution (per 10, 000 population) (2.7 in 2010 and 4.93 in 2016). This is 4.6 times less than the required global target recommended to effectively provide essential health services, meet the universal health coverage and health-related SDGs (i.e. 22.8/10,000) [56-58]. The effect this gap is clearly visible by showing that about $97 \%$ of hypertensive patients were not receiving appropriate preventive care $[9,10]$.

\section{Discussions}

In this review we evaluated five national guidelines and one international guideline used for management of high blood pressure in adults. The quality and comprehensiveness of National guideline for major NCDs of Ethiopia were evaluated based on clinical guideline appraisal tool [19-22] and comprehensiveness evaluation tool developed by the research team.

Only $12(50 \%)$ of ADAPTE process steps were addressed in National adult hypertension treatment guideline of Ethiopia [27]. The guidelines used for adaptation were not clearly mentioned, there quality is not assessed by validated instruments Like AGREE [59]. Generally, the guideline lacks engagement of all relevant stakeholders. Involving end-users is important to; address questions relevant to consumers, prioritize focus areas and improve acceptance [25].

Ethiopian national adult hypertension treatment guideline metonly $22(64.7 \%)$ of guideline quality standards [27]. Major problems of the guideline include; lack ofevidences evaluation to contextualization, incomplete adaptation of evidences and poor involvement of relevant stakeholders including end-users. This might be reason for poor dissemination of the guideline as evidenced by only $9 \%$ of health facilities have guidelines for CVD prevention and control [9].

Similarly, the guideline was the least comprehensive 15 (51.7\%) [27]. Major content problem werelack of diagnostic approach for masked, white-coat and resistant hypertension. The guideline did not address the genetic predisposition, child hood risk factors and secondary cases of hypertension. Similarly, management of hypertension in patients undergoing surgery, specific patient groups, Access to medicine and social determinants of health are not included in the guideline [27].

Regarding Blood pressure targets, ACC/AHA and HEART's target BP $<130 / 80 \mathrm{mmHg}$ for high risk and BP $<140 / 90 \mathrm{mmHg}$ for others. Australian and Canadian guidelines targets BP $<120 / 80$ for high risk, BP $<140 / 90$ $\mathrm{mmHg}$ for others. European hypertension society guideline targets $\mathrm{BP}<140 / 90 \mathrm{mmHg}$ in all patients and if treatment is tolerable $<130 / 80 \mathrm{mmHg}, 120-129 /<80$ $\mathrm{mmHg}$ for patients less than 65 years old and $130-139 /<$ $80 \mathrm{mmHg}$ in $\geq 65$ years $[1,12,14-18,34]$. Blood Pressure goal all these guidelines is based on SPRINT trial [60] and meta-analysis of 19 global blood pressure trials [61].

Ethiopian guideline for major NCDs targets BP < $140 / 90 \mathrm{mmHg}$ for adults $18-75$ years and $\mathrm{BP}<150 / 90$ $\mathrm{mmHg}$ for patients above 75 years of age [27]. However, mortality from NCDs in developing countries including Ethiopia is Premature (i.e. below 70 years) [9]. Therefore targeting population above 75 years in country where life expectancy is 65 years requires reconsideration of this recommendation and it is not supported by evidence.

HEART's technical package [15] and major NCDs guideline of Ethiopia [27] have similar BP targets. This is in line with the recent Cochrane review evidence which indicated no change in mortality or no differences in serious adverse events intargeting blood pressure targets ( $\leq 135 / 85 \mathrm{mmHg}$ ) when compared with 'standard' blood pressure targets ( $\leq 140$ to $160 / 90$ to $100 \mathrm{mmHg}$ ). There is insufficient evidence to justify lower blood pressure targets ( $\leq 135 / 85 \mathrm{mmHg}$ ) in people with hypertension and established CVD [62].

Race and ethnicity are becoming important for hypertension treatment and control. This is because of genetic variation and differences in social determinants of health. For example, Hypertension in black patients as compared with white patients tends to be more common, to present earlier in life, to be more severe and rapidly progressive [63]. Black patients are at significantly greater risk for stroke than white patients, especially at younger ages, due in part to the earlier onset and greater severity of hypertension. The adjusted relative risk of stroke, for example, is more than twice as high in hypertensive black patients aged 45-64 years as compared with similarly aged hypertensive white patients [64].

The Important risk factors for hypertension among black patients include: Lower socioeconomic status, Ingestion of a high-sodium/low-potassium diet, is poor maternal nutrition leading to low birth weight in the infant [65]. Use of CCBs and thiazides as first line therapy 
over ACEls for uncomplicated hypertension in blacks is recommended [1]. This may be associated with the maternal nutritional problems and low birth weight which could contribute development of few functional nephrons [65].

A Patient follow-up, monitoring BP targets and dose intensification of drugs or introduction of combination modalities are important for controlling blood pressure. The HEARTs technical Package [15] clearly described the duration of BP monitoring and dose intensification or addition of another drug if $\mathrm{BP}$ is not controlled. Ethiopian NCD guideline states starting at low doses and increasing dose step by step to maximum tolerated dose. But it did not describe when and how to intensify drug therapy [27]. This could contribute to under treatment of patients that could have benefited from appropriate intensification of drug therapy.

Access to medicines and basic technologies for hypertension prevention and control was not addressed in Ethiopian NCD guideline [27]. About $80 \%$ of deaths due to chronic illnesses in low and middle income countries (LMICS) are due to poor access to basic services in primary health care; lack of affordable laboratory tests and medicines and poor adherence to treatment $[10,66,67]$. According to the third national pharmaceutical sector survey percentage availability of medicines used for chronic illnesswas $54.55 \%$ which is below WHO target (i.e. $80 \%$ ). In addition this none of essential medicines for NCDs were affordable [52].

Healthcare service delivery system availability and Readiness survey indicated that thegeneral service readiness index was $54 \%$. Concerning readiness and availability of CVD care, the availability of diagnosis and/or management of CVD service was $41 \%$. Only $9 \%$ of facilities had Guidelines for CVD diagnosis and management $[9,55]$. Improving health system capacity to provide comprehensive CVD care is important.

Health Literacy is not well addressed as component of care in National NCD guideline of Ethiopia.Enhancing the health literacy of individuals and communities is an important measure to improve acceptability of NCD interventions $[12,68]$. Different studies indicated association between low literacy, with uncontrolled BP, low medication adherence $[69,70]$.

Another important but ignored component of care in Ethiopian guideline was social determinants of health. Findings from different literatures indicated that clinical care contributes only $10-20 \%$ to health outcomes of a person even in their best possible stand. Socioeconomic factors, health behavior and factors related to the physical environment are estimated to account for up to $80 \%$ of health outcomes [37]. Therefore creating local social support system for economically disadvantage groups may give opportunity to achieve treatment goals.

\section{Conclusion}

In conclusion, quality and comprehensiveness of Hypertension treatment guideline of Ethiopia is suboptimal. Major quality problems include lack of literature evaluation for contextualizationof evidences and lack of consideration to specific patient populations. Major comprehensiveness problemswerelack of diagnostic approach for masked, white-coat and resistant hypertension. Similarly, Access to medicine and social determinants of health are not addressed in the guideline.

Therefore, we recommend the guideline development committee and other relevant stakeholders to: update the blood pressure targets and age classification of elderly population, determine when to initiateand intensify antihypertensive drug therapy; address social determinants and socioeconomic status of population including maternal nutrition and Access of medicines. It is also important to enhance dissemination of guideline to all health facilities to provide standardized care to all patients with hypertension.

\section{Declarations}

\section{Ethics approval and consent to participate}

Not applicable.

\section{Consent for publication}

Not applicable.

\section{Availability of data and materials}

Not Applicable. This is systematic review and we have used only published articles.

\section{Competing interests}

The authors declare that they have no competing interests.

\section{Funding}

There is no funding source for the study.

\section{Authors' contributions}

All Authors read and approved the manuscript. MM: has framed the format design conducted the review and developed the manuscript for publication; MD: has conceived the review project; AA: participated in literature review and format design, participated in literature review and polished the language of the manuscript.

\section{Acknowledgements}

We would like to thank all Tehran University medical sciences, department of pharmacoeconomics and Pharmaceutical Administration staffs for their technical and material support during our review including access to Internet.

\section{References}

1. Whelton PK, Carey RM, Aronow WS, Casey DE Jr, Collins 
$\mathrm{KJ}$, et al. (2018) 2017 ACC/AHA/AAPA/ABC/ACPM/AGS/ APhA/ASH/ ASPC/NMA/PCNA guideline for the prevention, detection, evaluation, and management of high blood pressure in adults: a report of the American College of Cardiology/American Heart Association Task Force on Clinical Practice Guidelines. Hypertension 71: 1269-1324.

2. Risk Factors Collaborators (2018) Global, regional, and national comparative risk assessment of 84 behavioral, environmental and occupational, and metabolic risks or clusters of risks for 195 countries and territories, 1990-2017: A systematic analysis for the Global Burden of Disease Study 2017. Lancet 392: 1923-1994.

3. Kearney PM, Whelton M, Reynolds K, Muntner P, Whelton PK, et al. (2005) Global burden of hypertension: Analysis of worldwide data. Lancet 365: 217-223.

4. NCD Risk Factor Collaboration (2016) Worldwide trends in blood pressure from 1975 to 2015: A pooled analysis of 1479 population-based measurement studies with 19.1 million participants. Lancet 389: 37-55.

5. Geldsetzer P, Manne-Goehler J, Marcus ME, Ebert C, Zhumadilov Z, et al. (2019) The state of hypertension care in 44 low-income and middle-income countries: a cross-sectional study of nationally representative individual-level data from 1.1 million adults. Lancet 394: 652-662.

6. Ayalew T. Muluneh, Abraham Haileamlak, Fasil Tessema, Fessahaye Alemseged, Kifle Woldemichael, et al. (2012) Population based survey of chronic non-communicable diseases at gilgel gibe field research center, southwest Ethiopia. . Ethiop J Health Sci 22: 7-18.

7. Ethiopian Public Health Institute (2016) Ethiopia steps report on risk factors for chronic non-communicable diseases and prevalence of selected NCDs.

8. Kelemu Tilahun Kibret, Mesfin YM (2015) Prevalence of hypertension in Ethiopia: a systematic meta-analysis. Public Health Reviews 36.

9. Shiferaw F, Letebo M, Misganaw A, Feleke $Y$, Gelibo T, et al. (2018) Non-communicable Diseases in Ethiopia: Disease burden, gaps in health care delivery and strategic directions. Ethiopian Journal of Health Development 32.

10. World Health Organization (2013) Global action plan for the prevention and control of noncommunicable diseases 2013-2020.

11. WHO (2017) Health Profile: Ethiopia. World Health Rankings.

12. World Health Organization (2019) WHO independent high-level commission on noncommunicable diseases final report: It's time to walk the talk. World Health Organization, Geneva.

13. Ramirez-Morera A, Tristan M, Vazquez JC (2019) Effects of evidence-based clinical practice guidelines in cardiovascular health care quality improvements: A systematic review. F1000Res 8: 1041.

14. World Health Organization (2007) Prevention of Cardiovascular Disease: Guidelines for assessment and management of total cardiovascular risk.

15. WHO (2016) HEARTS: Technical package for cardiovascular disease management in primary health care. World Health Organization, Geneva.

16. Gabb GM, Mangoni AA, Anderson CS, Cowley D, Dowden JS, et al. (2016) Guideline for the diagnosis and management of hypertension in adults-2016. Medical Journal of Australia 205: 85-89.
17. Leung AA, Daskalopoulou SS, Dasgupta K, McBrien K, Butalia S, et al. (2017) Hypertension Canada's 2017 guidelines for diagnosis, risk assessment, prevention, and treatment of hypertension in adults. Canadian Journal of Cardiology 33: 557-576.

18. Williams B, Mancia G, Spiering W, Agabiti Rosei E, Azizi M, et al. (2018) 2018 Practice guidelines for the management of arterial hypertension of the European Society of Cardiology and the European Society of Hypertension. European Heart Journal 39: 3021-3104.

19. Siering U, Eikermann M, Hausner E, Hoffmann-Eßer W, Neugebauer EA (2013) Appraisal tools for clinical practice guidelines: a systematic review. PLoS One 8: e82915.

20. Steinberg E, Greenfield S, Wolman DM, Mancher M, Graham R (2011) Clinical practice guidelines we can trust: National Academies Press.

21. Eikermann M, Holzmann N, Siering U, Rüther A (2014) Tools for assessing the content of guidelines are needed to enable their effective use--a systematic comparison. BMC research notes 7: 853 .

22. Grilli R, Magrini N, Penna A, Mura G, Liberati A (2000) Practice guidelines developed by specialty societies: the need for a critical appraisal. The Lancet 355: 103-106.

23. Harrison MB, Légaré F, Graham ID, Fervers B (2010) Adapting clinical practice guidelines to local context and assessing barriers to their use. CMAJ 182: E78-E84.

24. Ansari S, Rashidian A (2012) Guidelines for guidelines: are they up to the task? A comparative assessment of clinical practice guideline development handbooks. PLoS One 7: e49864.

25. SIGN (2014) SIGN 50: a guideline developer's handbook. SIGN publication, Edinburgh.

26. MSH (2012) MDS-3: Managing Access to Medicines and Health technologies Management Sciences for Health.

27. Federal Democratic Republic of Ethiopia Ministry of Health (2016) Guidelines on Clinical and Programmatic Management of Major Non Communicable Diseases.

28. Alma J. Adler, Dorairaj Prabhakaran, Pascal Bovet, Dhruv S. Kazi, Giuseppe Mancia, et al. (2015) Reducing cardiovascular mortality through prevention and management of raised blood pressure. A world heart federation road map. Global Heart 10: 111-122.

29. Chun-Song Hu, Ya-Ling Han, Jun-Bo Ge, Qing-Hua Wu, Yan-Na Liu, et al. (2015) A novel management program for hypertension. Cardiovasc Diagn Ther 5: 316-322.

30. Babić B, Bagatin J, Kokic S, Ostojić S, Carević V, et al. (2009) Comparison between continuous ambulatory arterial blood pressure monitoring and standard blood pressure measurements among patients of younger and older age group. Collegium antropologicum 33: 65-70.

31. Margaret A Piper, Corinne V. Evans, Brittany U. Burda, Karen L. Margolis, Elizabeth O'Connor, et al. (2014) Screening for High Blood Pressure in Adults: A Systematic Evidence Review for the U.S. Preventive Services Task Force. Evidence Synthesis. AHRQ Publication, US.

32. Abel N, Contino K, Jain N, Grewal N, Grand E, et al. (2015) Eighth joint national committee (JNC-8) guidelines and the outpatient management of hypertension in the African-American population. North American journal of medical sciences 7: 438-445.

33. Chobanian AV, Bakris GL, Black HR, Cushman WC, Green LA, et al. (2003) The seventh report of the joint national 
committee on prevention, detection, evaluation, and treatment of high blood pressure: The JNC 7 report. JAMA 289: 2560-2571.

34. Reboussin DM, Norrina BA, Griswold ME, Guallar E, Hong $Y$, et al. (2017) Systematic review for the 2017 ACC/AHA/ AAPA/ABC/ACPM/AGS/APhA/ASH/ASPC/NMA/PCNA guideline for the prevention, detection, evaluation, and management of high blood pressure in adults: A Report of the American College of Cardiology/American Heart Association Task Force on Clinical Practice Guidelines. Hypertension 71: 2176-2198.

35. Arnett DK, Blumenthal RS, Albert MA, Buroker AB, Goldberger ZD, et al. (2019) ACC/AHA guideline on the primary prevention of cardiovascular disease: executive summary: a report of the American College of Cardiology/American Heart Association Task Force on Clinical Practice Guidelines. Circulation 140: e563-e595.

36. Jarari N, Rao N, Peela JR, Ellafi KA, Shakila S, et al. (2016) A review on prescribing patterns of antihypertensive drugs. Clinical Hypertension 22: 7.

37. Hood CM, Gennuso KP, Catlin BB (2016) County health rankings: Relationships between determinant factors and health outcomes. American Journal of Preventive Medicine 50: 129-135.

38. Folland S, Goodman A, Stano M (2013) The Economics of Health and Healthcare. Pearson.

39. Goldman LR, Benjamin GC, Hernández SR, Kindig DA, Kumanyika SK, et al. (2016) Advancing the Health of Communities and Populations: A Vital Direction for Health and Health Care. NAM Perspectives. Discussion Paper, National Academy of Medicine.

40. Fox AM (2012) The HIV-poverty thesis re-examined: Poverty, wealth or inequality as a social determinant of HIV infection in sub-Saharan Africa? Journal of biosocial science 44: 459-480.

41. Ammouri AA, Neuberger G (2008) The Perception of Risk of Heart Disease Scale: Development and Psychometric Analysis. . Journal of Nursing Measurement 16: 83-97.

42. Kendig H, Loh V, Loughlin K, Byles J, Nazroo JY (2016) Pathways to Well-Being in Later Life: Socioeconomic and Health Determinants Across the Life Course of Australian Baby Boomers. Journal of population ageing 9: 49-67.

43. Cockerham W, Hamby CBW, Oates GR (2017) The social determinants of chronic disease. American Journal of Preventive Medicine 52: S5-S12.

44. WHO (2019) WHO report on the global tobacco epidemic 2019: Offer help to quit tobacco use.

45. World Health Organization (2008) WHO report on the global tobacco epidemic, 2008. The MPOWER package.

46. Powles J, Fahimi S, Micha R, Khatibzadeh S, Shi P, et al. (2013) Global, regional and national sodium intakes in 1990 and 2010: a systematic analysis of $24 \mathrm{~h}$ urinary sodium excretion and dietary surveys worldwide. BMJ open 3: e003733.

47. WHO (2016) The SHAKE technical package for salt reduction.

48. World Health Organization (2018) Global status report on alcohol and health 2018.

49. (2018) An Action Package To: Eliminate Industrially-Produced Trans-Fatty Acids.

50. Mende Mensa Sorato, Majid Davari, Kebriaeezadeh A
(2019) Health Care System Response to Cardiovascular Diseases, Trends from 2010-2018: Can Ethiopia Achieve 2025 Global Voluntary Targets for Non-Communicable Diseases from Cardiovascular Diseases Perspective? Explanatory Review of Available Literatures. Research \& Reviews: Journal of Medical and Health Sciences 9: 1-13.

51. Wall HK, Beagan BM, O'Neill HJ, Foell KM, Boddie-Willis CL (2008) Addressing stroke signs and symptoms through public education: the Stroke Heroes Act FAST campaign. Preventing chronic disease 5.

52. Gerba H, Yegezu Y, Ejigu E, G/Giorgis A (2017) Pharmaceutical Sector Assessment in Ethiopia: Food Medicine and health care administration and control authority 1-64.

53. FDRoEMoH (2015) Health sector transformation plan (2015/16-2019/20). Ministry of Health Addis, Ababa.

54. Federal Democratic Republic of Ethiopia (2010) Health Sector Development Program IV, 2010/11-2014/15. Ministry of Health, Addis Ababa.

55. Elzinga G, Jerene D, Mesfin G, Negussie S (2010) Human resources for health implications of scaling up for universal access to HIVIAIDS prevention, treatment, and care: Ethiopia Rapid Situational Analysis. Group GHWATW, Addis Ababa, Ethiopia.

56. (2013) A Universal Truth: No Health without a workforce. World Health Organization (WHO) Report.

57. Feyissa YM, Hanlon C, Emyu S, Cornick RV, Fairall L, et al. (2019) Using a mentorship model to localise the Practical Approach to Care Kit (PACK): from South Africa to Ethiopia. BMJ global health 3: e001108.

58. Alebachew A, Waddington C (2015) Improving health system efficiency: Ethiopia: human resources for health reforms.

59. Brouwers M, Kho M, Browman G, Burgers J, Cluzeau F, et al. (2010) AGREE II: advancing guideline development, reporting, and evaluation in health care. Preventive medicine 51: $421-424$

60. Group SR (2015) A randomized trial of intensive versus standard blood-pressure control. New England Journal of Medicine 373: 2103-2116.

61. Xie X, Atkins E, Lv J, Bennett A, Neal B, et al. (2016) Effects of intensive blood pressure lowering on cardiovascular and renal outcomes: updated systematic review and meta-analysis. The Lancet 387: 435-443.

62. Saiz LC, Gorricho J, Garjon J, Celaya MC, Erviti J, et al. (2018) Blood pressure targets for the treatment of people with hypertension and cardiovascular disease. The Cochrane database of systematic reviews 7: Cd010315.

63. Carson AP, Howard G, Burke GL, Shea S, Levitan EB, et al. (2011) Ethnic differences in hypertension incidence among middle-aged and older adults: the multi-ethnic study of atherosclerosis. Hypertension 57: 1101-1117.

64. Howard G, Lackland DT, Kleindorfer DO, Kissela BM, Moy CS, et al. (2013) Racial differences in the impact of elevated systolic blood pressure on stroke risk. JAMA internal medicine 173: 46-51.

65. Howard G, Cushman M, Moy CS, Oparil S, Muntner P, et al. (2018) Association of clinical and social factors with excess hypertension risk in black compared with white US adults. JAMA 320: 1338-1348.

66. WHO (2018) Saving lives, spending less: a strategic response to non-communicable diseases. 
67. FMOH (2010) Strengthening Chronic Disease Services in Ethiopia: Lessons Learned from HIVIAIDS Program Implementation A National-Level Conference. Ethiopia.

68. Heinrich C (2012) Health literacy: The sixth vital sign. Journal of the American Academy of Nurse Practitioners 24: 218-223.

69. McNaughton CD, Jacobson TA, Kripalani S (2014) Low literacy is associated with uncontrolled blood pressure in primary care patients with hypertension and heart disease. Patient Educ Couns 96: 165-170.

70. Darvishpour J, Omidi S, Farmanbar R (2016) The relationship between health literacy and hypertension treatment control and follow-up. Caspian Journal of Health Research 2: $1-8$. 